\title{
INFLUENCE OF AORTIC VALVE REPLACEMENT, PROSTHESIS TYPE, AND SIZE ON FUNCTIONAL OUTCOME AND VENTRICULAR MASS IN PATIENTS WITH AORTIC STENOSIS
}

Odd Bech-Hanssen, MD

Kenneth Caidahl, $\mathrm{MD}, \mathrm{PhD}^{\mathrm{a}}$

Björn Wall, MD

Pia Mykén, $\mathrm{MD}, \mathrm{PhD}^{\mathrm{b}}$

Sture Larsson, $\mathrm{MD}, \mathrm{PhD}^{\mathrm{b}}$

Ingemar Wallentin, $\mathrm{MD}, \mathrm{PhD}^{\mathrm{a}}$
Objectives: Two years after surgery for severe aortic stenosis, we prospectively evaluated the influence of aortic valve replacement, as well as valve type (mechanical or stented biologic) and size, on functional status, left ventricular function, and regression of mass. Methods: Patients who received either a mechanical $(n=95)$ or a biologic valve $(n=42)$ were studied by echocardiography before the operation and after 2 years. Results: The percentage of patients with severe dyspnea decreased from $53 \%$ to $13 \%(P=\mathbf{. 0 0 1})$. The cardiac index increased from mean 2.6 $\mathrm{L} / \mathrm{min}$ per square meter $(95 \% \mathrm{CI}: \mathbf{2 . 4 8 - 2 . 7 2} \mathrm{L} / \mathrm{min}$ per square meter) to 3.1 L/min per square meter $(95 \%$ CI: $2.94-3.26 \mathrm{~L} / \mathrm{min}$ per square meter; $P=.001)$. The percentage of the patients with mild-to-moderate diastolic dysfunction decreased from $43 \%$ to $18 \%(P=.001)$. The left ventricular mass index was reduced by $42.4 \mathrm{~g}$ (95\% CI: $35-50 \mathrm{~g} ; \boldsymbol{P}=.001)$. In comparison with biologic valves of the same size, mechanical valves produced a more pronounced reduction in mass index (overall difference 21.7 g; 95\% CI: 37.1-6.4 g; $P=.007)$ and a lower mean Doppler gradient (overall difference $4 \mathrm{~mm} \mathrm{Hg;} \mathrm{95 \%} \mathrm{CI:} \mathrm{2-6} \mathrm{mm} \mathrm{Hg;} P=.0002$ ). Conclusions: Patients undergoing aortic valve replacement had an improvement in functional status, as well as systolic and diastolic left ventricular function, and a reduction in left ventricular mass index, irrespective of prosthesis size and type. Mechanical valves are somewhat less obstructive than stented bioprosthetic valves of the same size. They are also associated with a concomitantly more pronounced reduction of left ventricular mass. (J Thorac Cardiovasc Surg 1999;118:57-65)
L eft ventricular (LV) hypertrophy is a known predictor of morbid events in asymptomatic hypertensive patients or otherwise healthy adults. ${ }^{1}$ In a study of patients with severe aortic stenosis, we found increased risk for early mortality among those with a small hypertrophic heart and narrow LV outflow tract. ${ }^{2}$ We are not aware of any study that documents the late prognostic importance of preoperative LV hypertrophy in aortic valve

From the Departments of Clinical Physiology and Thoracic and Cardiovascular Surgery, ${ }^{\mathrm{b}}$ Sahlgrenska University Hospital, Göteborg, Sweden.

The study was supported by grants from the Göteborg Medical Society, Sahlgrenska University Hospital, and the Swedish Heart and Lung Foundation.

Received for publication Dec 14, 1998; revisions requested Feb 19, 1999; revisions received March 17, 1999; accepted for publication March 17, 1999.

Address for reprints: Odd Bech-Hanssen, MD, Department of Clinical Physiology, Sahlgrenska University Hospital, SE-413 45 Göteborg, Sweden.

Copyright (๑) 1999 by Mosby, Inc.

$0022-5223 / 99 \$ 8.00+0 \quad \mathbf{1 2 / 1 / 9 8 5 8 8}$ replacement. However, there are studies that report improved survival with large prosthetic valves compared with small ones, and this might be due to less initial hypertrophy or a more pronounced reduction in LV mass.,

The regression in LV mass is likely to be influenced by the prosthetic valve type and size. A regression in LV mass after aortic valve replacement has been documented, ${ }^{5-7}$ but only a few studies describe the impact of valve size. ${ }^{5,6}$ One recent report on the importance of prosthetic type (stented and stentless biologic valves vs bileaflet mechanical valves) did not find any statistically significant differences in regression of LV mass, but the number of patients studied was small. ${ }^{8}$

The aims of the present study were to evaluate the effects of valve replacement per se and of valve type (mechanical or biologic) and size on postoperative LV mass and LV systolic and diastolic function.

\section{Patients and methods}

Study patients. Between January 1991 and August 1993, a representative previously described population of 239 patients 
underwent aortic valve replacement involving 3 different prosthetic valves. ${ }^{9}$ The majority $(n=213,89 \%)$ of the patients participated in a randomized trial and received either a mechanical prosthetic valve (St Jude Medical Inc, St Paul, Minn, $n=102$, or Omnicarbon, Medical Inc, Inver Grove Heights, Minn, $n=63$ ) or a bioprosthesis (Biocor Industria e Pesquisas Ltd, Belo Horizonte, Brazil, $n=74$ ). Patients with a narrow aortic root (valve size 19 or $21 \mathrm{~mm}$ ) received either a St Jude Medical or Omnicarbon mechanical prosthesis. Patients with severe aortic regurgitation $(n=52)$, concomitant mitral surgery $(n=7)$, a small bioprosthesis (valve size 21 $\mathrm{mm}, \mathrm{n}=3$ ), a large prosthesis (valve size $29 \mathrm{~mm}, \mathrm{n}=2$ ), and prosthesis obstruction $(n=1)$ were excluded. The remaining population comprised 174 patients (mechanical $=122$, bio$\operatorname{logic}=52$ ). Inasmuch as 19 patients died, 16 patients declined further participation, and 2 were not evaluated before the operation, altogether 137 patients (mechanical valves $=95$, biologic valves $=42$ ) were investigated both before and approximately 2 years after the operation. At the late follow-up the patients received a questionnaire, they were interviewed about preoperative and late postoperative symptoms (dyspnea and angina), and their functional status was classified according to the New York Heart Association (NYHA). Informed consent was obtained from all patients and the study was approved by the Human Ethics Committee at Sahlgrenska University Hospital.

The St Jude Medical Standard Valve is a bileaflet pyrolytic carbon valve with an 85-degree leaflet angle in the open position. The monoleaflet Omnicarbon valve consists of pyrolytic carbon with a maximum opening angle of 80 degrees. The Biocor valve used in this study is a stented, glutaraldehydepreserved porcine bioprosthesis. The Biocor valve design allows both intra-annular and supra-annular insertion, but during the study period only the intra-annular position was used.

M-mode and 2-dimensional echocardiography. Echocardiography was performed with an Acuson 128 or 128XP Computed Sonograph (Acuson, Mountain View, Calif) or a Vingmed CFM 750 device (Vingmed Sound AS, Horten, Norway, 17 investigations). Both M-mode recordings and offline measurements were guided by the 2-dimensional image. M-mode measurements were made according to the recommendations of the American Society of Echocardiography. ${ }^{10}$ The ejection fraction was calculated according to Teichholz and associates ${ }^{11}$ and the LV mass by means of the cube formula. ${ }^{12}$

Doppler measurements. Blood flow velocity in the LV outflow tract was estimated by pulsed wave Doppler from an apical 4-chamber view (sample size of $5 \mathrm{~mm}$ ). Mitral flow was recorded between the mitral leaflets in the 4-chamber view. From the mitral velocity tracings (paper speed 100 $\mathrm{mm} / \mathrm{s}$ ), early flow velocity (E), deceleration time of $\mathrm{E}$ wave, and peak velocity during atrial systole (A) were measured. Pulmonary venous flow velocities were obtained from the upper right pulmonary vein (paper speed $50 \mathrm{~mm} / \mathrm{s}$ ). Peak velocities during systole (S) and diastole (D) were measured. Continuous wave Doppler signals were recorded from multiple windows by a 2-MHZ non-imaging probe.
The stroke volume was calculated as the product of the cross-sectional area of the LV outflow tract (CSA) and the velocity time integral (VTILVOT). The cardiac index was calculated as the product of heart rate and stroke volume divided by the body surface area. Pressure gradients were calculated according to the simplified Bernoulli equation $\left(\right.$ Doppler pressure gradient $\left.=4 \times[\text { peak velocity }]^{2}\right)$. The mean gradients were calculated from off-line planimetry of the continuous wave Doppler recordings. The effective orifice area was calculated according to the integral method: Effective orifice area $=\mathrm{CSA} \times($ VTILVOT/VTImax $) .{ }^{13}$

Normal limits and patterns describing diastolic function. The diastolic function was evaluated by integrating mitral flow and pulmonary venous information. Three different filling patterns were described: type A, normal diastolic function; type B, normal mitral E/A ratio and S/D ratio, mildto-moderate diastolic dysfunction with normal or slightly increased LV filling pressure, decreased E/A ratio, and normal S/D; and type $\mathrm{C}$, severe diastolic dysfunction with increased LV filling pressure, decreased S/D ratio, and normal or increased E/A ratio. The normal limits for mitral flow E/A and pulmonary venous flow S/D ratios were defined as being within $90 \%$ of the normal distribution (mean \pm 1.65 standard deviation). The healthy control group consisted of 33 men and 27 women without hypertension or diabetes mellitus, with a normal resting electrocardiogram, and without any history of heart disease. The mitral and pulmonary venous flow parameters describing diastolic function are age dependent. ${ }^{14}$ We therefore made a separate determination of the normal limits for mitral flow E/A ratio and pulmonary venous S/D ratio for patients less than 60 years old and 60 years of age or older.

Statistics. Continuous variables are summarized with the use of mean and standard deviation. Categoric variables are summarized with the use of absolute and relative frequencies. Differences between investigations were evaluated by means of a paired Student $t$ test. Proportions between patient groups were tested by use of a $\chi^{2}$ test, and changes in proportions within a group of patients were tested by the Wilcoxon signed rank test. The results for the primary efficacy variables are presented together with $95 \%$ confidence intervals (CI). No adjustments for multiple statistical testing were performed. The relationship between prosthesis size and Doppler echocardiographic variables was evaluated by simple linear regression analysis calculating $R^{2}$ (Pearson's coefficient of variation). A multiple regression analysis was performed to identify factors important to LV mass reduction and mean Doppler gradient across the prosthesis. The variables tested for LV mass reduction were age, sex, severity of aortic stenosis (mean pressure gradient), blood pressure, and prosthesis characteristics (type, size, mean prosthesis gradient, and effective orifice area). In the case of the mean Doppler gradient across the prosthesis, the variables tested were body size (body surface area), flow through the prosthesis (cardiac index), and prosthesis characteristics (type and size).

Interobserver and intraobserver variability. At our laboratory, the interobserver/intraobserver variability, defined as 
Table I. Preoperative and postoperative clinical characteristics of patients receiving a mechanical (St Jude Medical, $n=67$, Omnicarbon, $n=28$ ) or a biologic (Biocor, $n=42$ ) prosthetic valve in the aortic position

\begin{tabular}{|c|c|c|c|}
\hline & Mechanical $(n=95)$ & Biologic $(n=42)$ & $\mathrm{P}$ value \\
\hline Female $(\%)$ & 54 & 36 & .052 \\
\hline CABG $(\%)$ & 27 & 36 & .325 \\
\hline Age at operation $(y)$ & $70 \pm 7.8$ & $69 \pm 9.2$ & $>.40$ \\
\hline Mean pressure gradient (mm Hg) & $61 \pm 19.4$ & $61 \pm 17.2$ & $>.40$ \\
\hline Aortic valve area index $\left(\mathrm{cm}^{2} / \mathrm{m}^{2}\right)$ & $0.35 \pm 0.10$ & $0.36 \pm 0.12$ & $>.40$ \\
\hline $\begin{array}{l}\text { Distribution of valve sizes: } 19 \mathrm{~mm}, 21 \mathrm{~mm} \text {, } \\
23 \mathrm{~mm}, 25 \mathrm{~mm}, 27 \mathrm{~mm} \mathrm{( \% )}\end{array}$ & $7,26,34,27,5$ & $0,0,40,36,24$ & .001 \\
\hline
\end{tabular}

$P$ values are given for comparison of mechanical and biologic valves. Values are mean \pm standard deviation. $C A B G$, Coronary artery bypass grafting.

the mean value of difference/mean value of measurements in percent, is as follows; for 2-dimensionally guided M-mode echocardiography (LV diameter in diastole), 1\%/1\%; Doppler measurements (mitral early deceleration time), $5 \% / 12 \%$; calculations based on Doppler measurements (E/A ratio), $9 \% / 8 \%$; calculations based on 2-dimensional and Doppler measurements (effective orifice area), $2 \% / 1 \%$; and LV mass calculations based on M-mode echocardiography, $11 \% / 4 \%$.

\section{Results}

Clinical characteristics. Patients who received a mechanical prosthesis were investigated $27 \pm 6.6$ months after the operation, and patients with a biologic prosthesis were investigated $25 \pm 5.2$ months after the operation $(P=.105)$. The female dominance in the mechanical valve group was due to the fact that only women received $19-\mathrm{mm}$ valves and $92 \%$ of the patients with size 21-mm prostheses were women (Table I). Of 32 patients with a prosthetic valve size 19 or $21 \mathrm{~mm}, 30$ were older than 60 years of age. Patients with mechanical prostheses were comparable with patients with bioprostheses in terms of severity of aortic valve disease.

The patients who were not alive 2 years after the operation were older than the study subjects $(75 \pm 5.7$ vs $70 \pm 8.2$ years; $P=.01)$. The cause of death was heart failure or infarction in all of those $(6 / 19,46 \%)$ who had an early death ( $\leq 30$ days after valve replacement), whereas the cause was noncardiac in $46 \%$ of those who died later (13/19). The patients who were not alive at follow-up and the patients who did not want to participate had similar preoperative Doppler echocardiographic findings (stenosis severity, ejection fraction, LV mass, and diastolic function parameters) compared with the study subjects.

Influence of aortic valve replacement. The preoperative functional status assessed according to the NYHA classification was comparable for patients with mechanical valves and patients with biologic valves. Dyspnea was the dominant preoperative symptom. The percentage of patients with severe dyspnea (NYHA classes III and IV) decreased from $53 \%$ to $13 \%(P=$ $.001)$ and with angina from $31 \%$ to $7 \%(P=.001)$. There was no difference in the effect of valve replacement between mechanical and bioprosthetic valves.

LV diastolic and systolic diameter indexed to body surface area decreased and the ejection fraction and cardiac index increased (Tables IIa and IIb). The ejection fraction increased from 62\% (95\% CI: 59.7\%$64.7 \%)$ to $65 \%(95 \% \mathrm{CI}: 62.2 \%-67 \%)(P=.002)$ in the postoperative period, whereas the cardiac index increased from $2.6 \mathrm{~L} / \mathrm{min}$ per square meter $(95 \% \mathrm{CI}$ : 2.48-2.72 L/min per square meter) to $3.1 \mathrm{~L} / \mathrm{min}$ per square meter $(95 \% \mathrm{CI}: 2.94-3.26 \mathrm{~L} / \mathrm{min}$ per square meter) $(P=.001)$. The proportion of patients who had an increase in ejection fraction was $64 \%$, whereas the figure for cardiac index was $72 \%$. Fig 1 shows that the effects of aortic valve replacement on ejection fraction were most pronounced among patients with a severely reduced ejection fraction before the operation. The proportion of patients with normal diastolic function (type A) assessed from mitral and pulmonary venous velocity recordings increased because of a reduction in the number of patients with mild-to-moderate diastolic dysfunction (type B) (Fig 2). There were no statistically significant differences between mechanical and biologic valves. After aortic valve replacement, the LV mass index decreased $42.4 \mathrm{~g}$ (95\% CI: 35-50 g), which constitutes a reduction of $24 \%$ (95\% CI: $20 \%-28 \%)$.

Influence of valve size and type. For both mechanical and biologic prostheses, the mean Doppler gradients decreased and the effective orifice area and effective orifice area index increased with increasing valve size (Table III). Fig 3 shows that the strength of the relationship (slope) to valve size was strongest for effective orifice area and lower for mean gradient. Prosthetic valve size could explain $41 \%$ (mechanical) and $50 \%$ (biologic) of the variability in effective orifice area, whereas the corresponding percentages for mean Doppler gradi- 
Table IIa. Preoperative and postoperative echocardiographic data related to LV systolic and diastolic function in mechanical prosthetic valves

\begin{tabular}{|c|c|c|c|c|c|c|c|}
\hline & Preoperative & $n$ & Postoperative & $n$ & Mean difference & $n$ & $\mathrm{P}$ value \\
\hline LVd index $\left(\mathrm{cm} / \mathrm{m}^{2}\right)$ & $\begin{array}{c}2.91 \pm 0.35 \\
(2.82 \text { to } 3.00)\end{array}$ & 61 & $\begin{array}{c}2.79 \pm 0.44 \\
(2.69 \text { to } 2.89)\end{array}$ & 76 & $\begin{array}{c}0.15 \pm 0.37 \\
(0.05 \text { to } 0.25)\end{array}$ & 57 & .004 \\
\hline LVs index $\left(\mathrm{cm} / \mathrm{m}^{2}\right)$ & $\begin{array}{c}1.91 \pm 0.43 \\
(1.80 \text { to } 2.02)\end{array}$ & 61 & $\begin{array}{c}1.78 \pm 0.48 \\
(1.67 \text { to } 1.89)\end{array}$ & 76 & $\begin{array}{c}0.18 \pm 0.40 \\
(0.07 \text { to } 0.28)\end{array}$ & 57 & .002 \\
\hline Ejection fraction (\%) & $\begin{array}{c}62.5 \pm 13.3 \\
(59.2 \text { to } 65.8)\end{array}$ & 61 & $\begin{array}{c}65.9 \pm 11.3 \\
(63.3 \text { to } 68.5)\end{array}$ & 74 & $\begin{array}{c}-3.9 \pm 12.4 \\
(-7.2 \text { to }-0.73)\end{array}$ & 56 & .019 \\
\hline Cardiac index $\left(\mathrm{L} / \mathrm{min} / \mathrm{m}^{2}\right)$ & $\begin{array}{c}2.55 \pm 0.76 \\
(2.40 \text { to } 2.70)\end{array}$ & 91 & $\begin{array}{c}3.04 \pm 0.88 \\
(2.86 \text { to } 3.22)\end{array}$ & 90 & $\begin{array}{l}-0.46 \pm 0.94 \\
(-0.65 \text { to }-0.26)\end{array}$ & 87 & .0001 \\
\hline $\mathrm{E} / \mathrm{A}$ ratio & $\begin{array}{c}1.0 \pm 0.74 \\
(0.84 \text { to } 1.16)\end{array}$ & 80 & $\begin{array}{c}1.02 \pm 0.31 \\
(0.98 \text { to } 1.06)\end{array}$ & 75 & $\begin{array}{c}-0.057 \pm 0.65 \\
(-0.21 \text { to } 0.09)\end{array}$ & 72 & $>.40$ \\
\hline $\mathrm{E} \operatorname{dec}(\mathrm{ms})$ & $\begin{array}{c}239 \pm 99.5 \\
(215 \text { to } 262)\end{array}$ & 70 & $\begin{array}{c}238 \pm 72.5 \\
(221 \text { to } 255)\end{array}$ & 72 & $\begin{array}{c}16 \pm 99 \\
(-9 \text { to } 43)\end{array}$ & 56 & .209 \\
\hline $\mathrm{S}$ velocity $(\mathrm{cm} / \mathrm{s})$ & $\begin{array}{c}55 \pm 16 \\
(51 \text { to } 59)\end{array}$ & 69 & $\begin{array}{c}56 \pm 14) \\
(52 \text { to } 60)\end{array}$ & 60 & $\begin{array}{c}0.02 \pm 0.16 \\
(-0.03 \text { to } 0.06)\end{array}$ & 48 & $>.40$ \\
\hline D velocity $(\mathrm{cm} / \mathrm{s})$ & $\begin{array}{c}45 \pm 16 \\
\text { (41 to } 49)\end{array}$ & 69 & $\begin{array}{l}47 \pm 13 \\
\text { (44 to } 50)\end{array}$ & 60 & $\begin{array}{l}-0.02 \pm 0.14 \\
(-0.04 \text { to } 0.01)\end{array}$ & 48 & .163 \\
\hline $\mathrm{S} / \mathrm{D}$ ratio & $\begin{array}{c}1.41 \pm 0.64 \\
(1.26 \text { to } 1.56)\end{array}$ & 69 & $\begin{array}{c}1.26 \pm 0.33 \\
(1.18 \text { to } 1.34)\end{array}$ & 60 & $\begin{array}{c}0.22 \pm 0.56 \\
(0.06 \text { to } 0.38)\end{array}$ & 48 & .0095 \\
\hline
\end{tabular}

Mean \pm standard deviation (95\% confidence interval). LVd index, LV diameter in diastole indexed to body surface area; $L V s$ index, LV diameter in systole indexed to body surface area; E/A ratio, ratio between early $(E)$ and late $(A)$ peak mitral velocity; $E$ dec, E wave deceleration time; $S$ velocity, peak velocity in pulmonary vein during systole; $D$ velocity, peak velocity in pulmonary vein during diastole.

Table IIb. Preoperative and postoperative echocardiographic data related to LV systolic and diastolic function in biologic prosthetic valves

\begin{tabular}{|c|c|c|c|c|c|c|c|}
\hline & Preoperative & $n$ & Postoperative & $n$ & Mean difference & $n$ & $\mathrm{P}$ value \\
\hline $\mathrm{LVd}$ index $\left(\mathrm{cm} / \mathrm{m}^{2}\right)$ & $\begin{array}{c}2.92 \pm 0.34 \\
(2.80 \text { to } 3.04)\end{array}$ & 33 & $\begin{array}{c}2.74 \pm 0.31 \\
(2.64 \text { to } 2.84)\end{array}$ & 35 & $\begin{array}{c}0.21 \pm 0.29 \\
(0.10 \text { to } 0.32)\end{array}$ & 28 & .0007 \\
\hline LVs index $\left(\mathrm{cm} / \mathrm{m}^{2}\right)$ & $\begin{array}{c}1.95 \pm 0.46 \\
(1.79 \text { to } 2.11)\end{array}$ & 33 & $\begin{array}{c}1.80 \pm 0.42 \\
(1.66 \text { to } 1.94)\end{array}$ & 35 & $\begin{array}{c}0.23 \pm 0.28 \\
(0.13 \text { to } 0.33)\end{array}$ & 28 & .0001 \\
\hline Ejection fraction (\%) & $\begin{array}{c}60.3 \pm 14.0 \\
(55.5 \text { to } 65.1)\end{array}$ & 33 & $\begin{array}{c}61.6 \pm 14.7 \\
(56.6 \text { to } 67.3)\end{array}$ & 33 & $\begin{array}{c}-4.4 \pm 10.3 \\
(-8.4 \text { to }-0.4)\end{array}$ & 26 & .038 \\
\hline Cardiac index $\left(\mathrm{L} / \mathrm{min} / \mathrm{m}^{2}\right)$ & $\begin{array}{c}2.63 \pm 0.91 \\
(2.35 \text { to } 2.91)\end{array}$ & 41 & $\begin{array}{c}3.14 \pm 0.86 \\
(2.88 \text { to } 3.40)\end{array}$ & 42 & $\begin{array}{c}0.53 \pm 1.03 \\
(-0.85 \text { to }-0.21)\end{array}$ & 41 & .0021 \\
\hline $\mathrm{E} / \mathrm{A}$ ratio & $\begin{array}{c}1.0 \pm 0.57 \\
(0.80 \text { to } 1.20)\end{array}$ & 32 & $\begin{array}{c}0.94 \pm 0.3 \\
(0.84 \text { to } 1.04)\end{array}$ & 34 & $\begin{array}{c}0.04 \pm 0.58 \\
(-0.18 \text { to } 0.26)\end{array}$ & 28 & $>.40$ \\
\hline $\mathrm{E} \operatorname{dec}(\mathrm{ms})$ & $\begin{array}{c}268 \pm 120 \\
(226 \text { to } 310)\end{array}$ & 31 & $\begin{array}{c}241 \pm 68 \\
(218 \text { to } 264)\end{array}$ & 33 & $\begin{array}{r}35 \pm 120 \\
(-11 \text { to } 79)\end{array}$ & 27 & .146 \\
\hline $\mathrm{S}$ velocity $(\mathrm{cm} / \mathrm{s})$ & $\begin{array}{c}56 \pm 16 \\
\text { (50 to } 62)\end{array}$ & 30 & $\begin{array}{c}62 \pm 13 \\
\text { (57 to } 67)\end{array}$ & 25 & $\begin{array}{l}-0.05 \pm 0.13 \\
(-0.10 \text { to } 0.01)\end{array}$ & 20 & .127 \\
\hline D velocity $(\mathrm{cm} / \mathrm{s})$ & $\begin{array}{c}47 \pm 16 \\
\text { (41 to } 53 \text { ) }\end{array}$ & 30 & $\begin{array}{c}52 \pm 13 \\
(47 \text { to } 57)\end{array}$ & 25 & $\begin{array}{l}-0.08 \pm 0.15 \\
(0.15 \text { to } 0.015)\end{array}$ & 20 & .027 \\
\hline $\mathrm{S} / \mathrm{D}$ ratio & $\begin{array}{c}1.36 \pm 0.58 \\
(1.15 \text { to } 1.57)\end{array}$ & 30 & $\begin{array}{c}1.29 \pm 0.53 \\
(1.08 \text { to } 1.50)\end{array}$ & 25 & $\begin{array}{c}0.16 \pm 0.49 \\
(-0.05 \text { to } 0.37)\end{array}$ & 20 & .154 \\
\hline
\end{tabular}

Mean \pm standard deviation (95\% confidence interval). $L V d$ index, LV diameter in diastole indexed to body surface area; $L V s$ index, LV diameter in systole indexed to body surface area; E/A ratio, ratio between early $(E)$ and late $(A)$ peak mitral velocity; $E$ dec, E wave deceleration time; $S$ velocity, peak velocity in pulmonary vein during systole; $D$ velocity, peak velocity in pulmonary vein during diastole.

ents were 18\% (mechanical) and 19\% (biologic). Table IV shows the results of a multiple regression analysis of factors important for LV mass index regression and mean prosthetic Doppler gradient. The mean pressure gradient in the native aortic valve, prosthetic valve type, and size played a statistically significant part in explain- ing LV mass index regression, whereas prosthesis mean gradient and effective orifice area did not. The LV mass index regression in mechanical valves was more pronounced than in biologic valves, with an overall difference of $21.7 \mathrm{~g}$ (95\% CI: 37.1-6.4 g) between mechanical and biologic valves of the same size. The effect on 


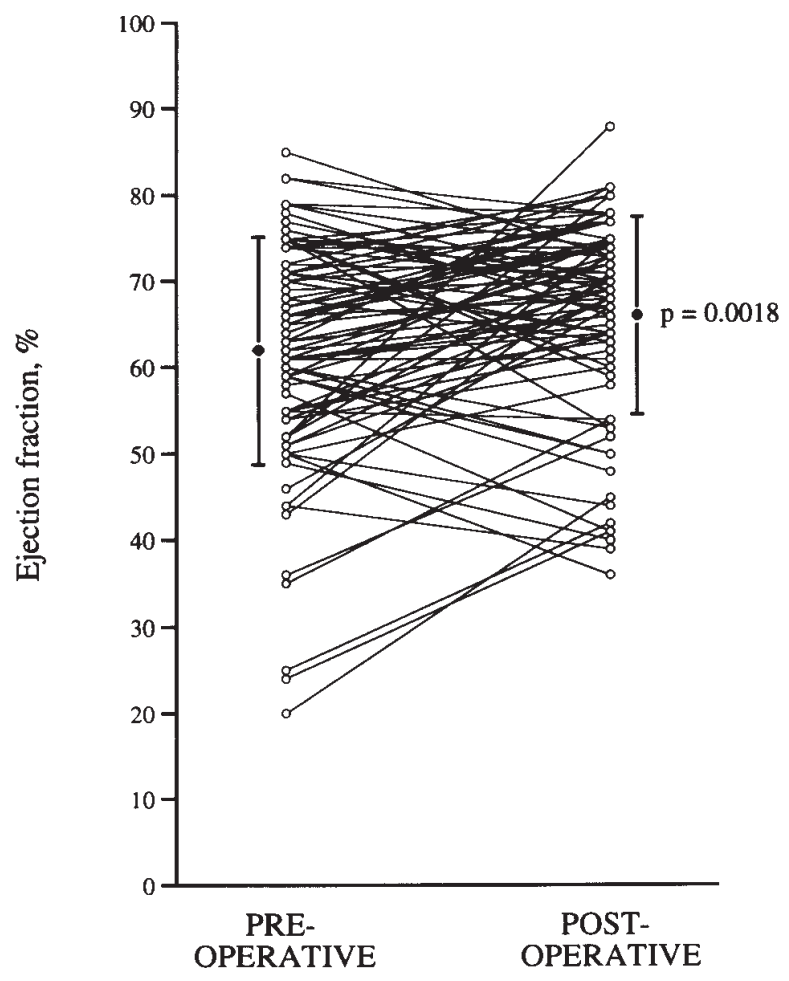

Fig 1. Effect of aortic valve replacement on ejection fraction $(\mathrm{n}=83)$.

LV mass index regression produced by increasing the valve size by $2 \mathrm{~mm}$ was $7.4 \mathrm{~g}$ (95\% CI: $0.5-14.7 \mathrm{~g})$. The multiple regression equation could explain $27 \%$ of the observed variability in LV mass index regression. Variables important to the mean prosthetic Doppler gradient were prosthetic size and type, cardiac index, and body surface area. Mechanical valves had lower mean Doppler gradients, with an overall difference of $4 \mathrm{~mm}$ $\mathrm{Hg}$ (95\% CI: 2-6.1 mm Hg) compared with biologic valves of the same size. The effect on mean prosthetic Doppler gradient produced by increasing the valve size by $2 \mathrm{~mm}$ was $4.2 \mathrm{~mm} \mathrm{Hg}$ (95\% CI: 5.4-3.0 $\mathrm{mm} \mathrm{Hg}$ ). The multiple regression equation could explain $36 \%$ of the observed variability in mean prosthetic Doppler gradient. Mechanical valves size $23 \mathrm{~mm}$ had a better hemodynamic performance with a lower mean pressure decrease $(P=.014)$ and a larger effective orifice area index $(P=.014)$ stented biologic valves of the same size. Mechanical valve size $21 \mathrm{~mm}$ was comparable with bioprosthesis size $23 \mathrm{~mm}$.

\section{Discussion}

Influence of aortic valve replacement. We found that aortic valve replacement produced effects such as regression in LV mass index and improved systolic and

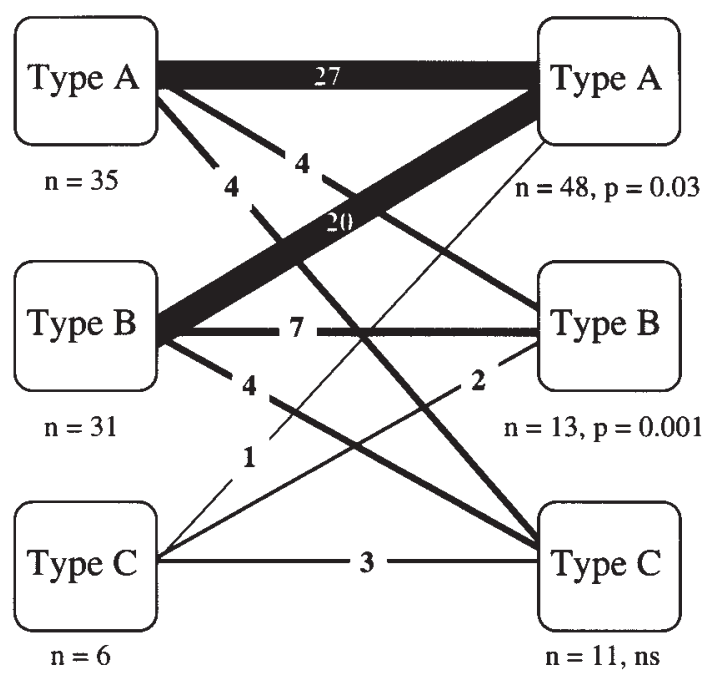

PREOPERATIVE

POSTOPERATIVE

Fig 2. Effect of aortic valve replacement on diastolic function. Type A, Normal diastolic function; type B, mild to moderate diastolic dysfunction with normal or slightly increased $\mathrm{LV}$ filling pressure; type $C$, severe diastolic dysfunction with increased LV filling pressure.

diastolic function. The magnitude of LV mass index regression in our study (24\%) was comparable with that noted by other investigators $(20 \%-34 \%)$. $^{5-1,15}$

Diastolic function improved, but 2 years after the operation a large proportion of the patients (34\%) still showed signs of disturbed filling properties and increased LV mass. This lack of normalization might be an expression of patient-prosthesis mismatch with an important LV pressure load. However, the patients were investigated 26 months after the operation (range 16-60 months), and this may be an insufficient period in which to achieve a regression in LV mass and diastolic dysfunction. Using hemodynamic and endomyocardial biopsy studies, Monrad, ${ }^{7}$ Krayenbuehl, ${ }^{16}$ and their associates have shown that the process of myocardial remodeling occurs over many years. They found that for patients with aortic stenosis undergoing aortic valve replacement, the LV mass index was reduced from $114 \mathrm{~g} / \mathrm{m}^{2}$ at an intermediate postoperative investigation $(1.6 \pm 0.5$ years $)$ to $97 \mathrm{~g} / \mathrm{m}^{2}$ at a late investigation $(8.1 \pm 2.9$ years $)$. Their studies myocardial structure revealed that the regression in LV mass at the intermediate stage after aortic valve replacement was due to a decrease in myocardial cellular hypertrophy with an increase in relative interstitial fibrosis. ${ }^{16}$ At the late investigation, the LV fibrous content also decreased. When the passive diastolic properties were determined at the intermediate stage, the patients had 

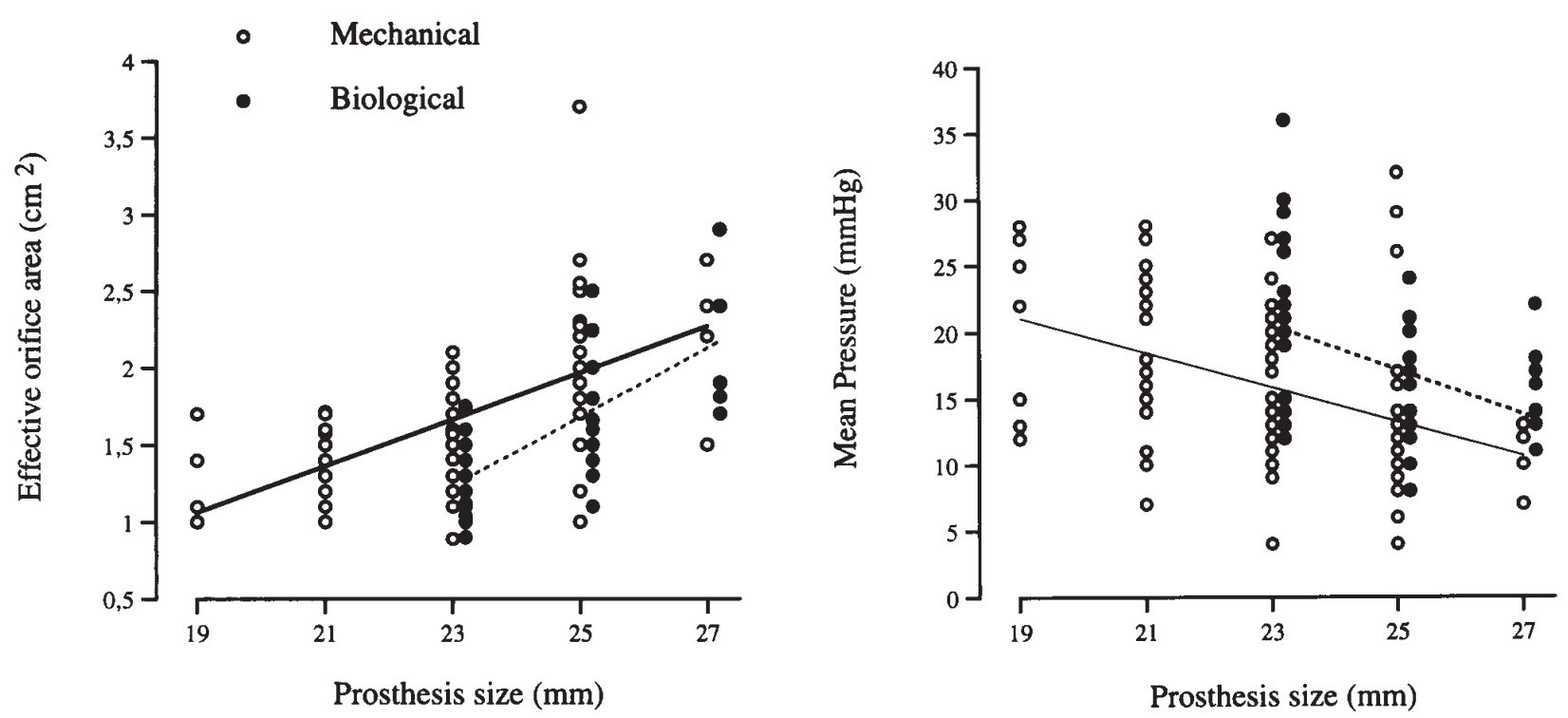

Fig 3. Left, Relationship between prosthesis size and effective orifice area. Linear regression for mechanical valves (solid line, $\mathrm{n}=92, \mathrm{y}=0.15 \mathrm{x}-1.8$, standard error of the slope $=0.02, r=0.63, P=.001$ ) and biologic valves (dashed line, $\mathrm{n}=41, \mathrm{y}=0.22 \mathrm{x}-3.8$, standard error of the slope $=0.035, r=0.71, P=.001$ ). Right, Relationship between prosthesis size and mean prosthetic Doppler gradient. Linear regression for mechanical valves (solid line, $\mathrm{n}=95, \mathrm{y}=45.8-1.3 \mathrm{x}$, standard error of the slope $=0.30, r=0.41, P=.001$ ) and biologic valves (dashed line, $\mathrm{n}=42, \mathrm{y}=58.7-1.7 \mathrm{x}$, standard error of the slope $=0.54, r=0.44, P=.004$ ).

increased myocardial stiffness, which normalized at a late stage after aortic valve replacement. ${ }^{17,18}$ From these studies, we can expect a further reduction in LV mass with less disturbed diastolic function in our patient group.

In our study, we found an improvement in systolic function with a decrease in diastolic and systolic dimensions and an increase in ejection fraction. The increase in ejection fraction was more than an adjustment to reduced LV volumes, inasmuch as the cardiac index was also increased. This finding is in accordance with those of other investigators, and improved systolic function has been shown to occur during the operation, immediately after aortic valve replacement.7,19 We observed a marked improvement in cardiac index and ejection fraction among patients with the most severe preoperative dysfunction, which implies that a decrease in preoperative ejection fraction caused by excess afterload does not preclude a postoperative improvement in LV function. Systolic dysfunction in patients with aortic stenosis is therefore due predominantly to afterload excess rather than to intrinsic myocardial damage.

Influence of prosthetic valve type and size. We found higher pressure gradients in biologic valves than in mechanical valves. This implies that the LV pressure is higher in patients with biologic valves, which could explain a less pronounced regression in LV mass index.
Our findings differ from those of others, for LV mass index decreased in patients with 19 and $21 \mathrm{~mm}$ valves. ${ }^{5,6}$ González-Juanatey, ${ }^{5} \mathrm{Sim}^{6}{ }^{6}$ and their colleagues both included patients with small biologic valves (8/12 and 8/10, respectively, receiving valve size $19 \mathrm{~mm}$ ), and they found no statistically significant regression in LV mass index in these groups of patients. In the present study, patients were investigated prospectively and randomized to either a mechanical or a biologic prosthesis with the important exception of those patients with a small aortic root (size 19 or 21 $\mathrm{mm}$ ), who all received a mechanical valve. This selection policy probably has influenced our results. The less pronounced regression of LV mass index reported by others could therefore be due to valve type rather than valve size.

Prosthesis-patient mismatch. In some patients with a large body surface area relative to aortic root dimensions, or in physically active individuals, can a small prosthetic valve cause an obstruction of hemodynamic importance?20,21 This prosthesis-patient mismatch has been claimed to be present at an effective orifice area index of $0.85 \mathrm{~cm}^{2} / \mathrm{m}^{2}$ or less. ${ }^{22}$ We found effective orifice area indices indicating prosthesis-patient mismatch in the majority of patients receiving valve sizes of 23 $\mathrm{mm}$ or smaller. It was therefore unexpected to find only 
Volume 118, Number 1

Table III. Clinical and echocardiographic data related to valve type and size

\begin{tabular}{|c|c|c|c|c|c|c|c|c|}
\hline & \multirow{2}{*}{$\begin{array}{c}\text { Size 19: } \\
\text { Mechanical } \\
\quad(n=7)\end{array}$} & \multirow{2}{*}{$\begin{array}{c}\text { Size 21: } \\
\text { Mechanical } \\
(n=25)\end{array}$} & \multicolumn{2}{|c|}{ Size 23} & \multicolumn{2}{|c|}{ Size 25} & \multicolumn{2}{|c|}{ Size 27} \\
\hline & & & $\begin{array}{l}\text { Mechanical } \\
\quad(n=25)\end{array}$ & $\begin{array}{l}\text { Biologic } \\
(n=17)\end{array}$ & $\begin{array}{c}\text { Mechanical } \\
\quad(n=26)\end{array}$ & $\begin{array}{l}\text { Biologic } \\
(n=15)\end{array}$ & $\begin{array}{c}\text { Mechanical } \\
\quad(n=5)\end{array}$ & $\begin{array}{l}\text { Biologic } \\
(n=10)\end{array}$ \\
\hline $\mathrm{BSA}\left(\mathrm{m}^{2}\right)$ & $1.64 \pm 0.12$ & $1.74 \pm 0.20$ & $1.82 \pm 0.17$ & $1.76 \pm 0.13$ & $1.91 \pm 0.17$ & $1.83 \pm 0.15$ & $1.93 \pm 0.12$ & $2.07 \pm 0.13$ \\
\hline Mean gradient $(\mathrm{mm} \mathrm{Hg})$ & $20 \pm 6.8$ & $18 \pm 6.0$ & $16 \pm 5.7$ & $21 \pm 6.9$ & $13 \pm 6.7$ & $15 \pm 4.3$ & $10 \pm 2.8$ & $15 \pm 3.6$ \\
\hline EOA index $\left(\mathrm{cm}^{2} / \mathrm{m}^{2}\right)$ & $0.76 \pm 0.17$ & $0.8 \pm 0.15$ & $0.87 \pm 0.20$ & $0.74 \pm 0.14$ & $1.1 \pm 0.27$ & $0.9 \pm 0.20$ & $1.2 \pm 0.28$ & $1.1 \pm 0.24$ \\
\hline Preop LVMI $\left(\mathrm{g} / \mathrm{m}^{2}\right)$ & $\begin{array}{l}144 \pm 21.0 \\
(128-152)\end{array}$ & $\begin{array}{l}156 \pm 40.9 \\
(135-177)\end{array}$ & $\begin{array}{l}167 \pm 39.5 \\
(149-185)\end{array}$ & $\begin{array}{l}176 \pm 35.6 \\
(155-197)\end{array}$ & $\begin{array}{l}147 \pm 25.5 \\
(134-160)\end{array}$ & $\begin{array}{l}153 \pm 31.0 \\
(134-172)\end{array}$ & $\begin{array}{l}209 \pm 41.3 \\
(173-245)\end{array}$ & $\begin{array}{l}174 \pm 32.6 \\
(148-200)\end{array}$ \\
\hline Postop LVMI (g/m²) & $\begin{array}{r}104 \pm 17.6 \\
(89-119)^{*}\end{array}$ & $\begin{array}{l}123 \pm 44.4 \\
(104-142) \ddagger\end{array}$ & $\begin{array}{l}127 \pm 27.1 \\
(116-138) \div\end{array}$ & $\begin{array}{l}129 \pm 26.9 \\
(114-144) \dagger\end{array}$ & $\begin{array}{r}119 \pm 50.8 \\
(97-141) \ddagger\end{array}$ & $\begin{array}{l}127 \pm 38.9 \\
(105-149)\end{array}$ & $\begin{array}{l}126 \pm 24.7 \\
(104-148) \dagger\end{array}$ & $\begin{array}{l}131 \pm 24.4 \\
(114-148) \dagger\end{array}$ \\
\hline$\Delta \operatorname{LVMI}\left(\mathrm{g} / \mathrm{m}^{2}\right)$ & $40 \pm 26.4$ & $43 \pm 28.1$ & $47 \pm 46.2$ & $32 \pm 25.5$ & $44 \pm 29.4$ & $24 \pm 38.8$ & $83 \pm 25.8$ & $41 \pm 16.6$ \\
\hline$\Delta$ LVMI $(\%)$ & $27 \pm 14.6$ & $27 \pm 13.5$ & $25 \pm 21.8$ & $18 \pm 14.9$ & $29 \pm 15.8$ & $15 \pm 24.6$ & $40 \pm 7.2$ & $24 \pm 5.6$ \\
\hline
\end{tabular}

Mean \pm standard deviation (95\% confidence interval). BSA, Body surface area; EOA index, effective orifice area indexed to body surface area; $L V M I$, LV mass index. $* P<.05$.

$\dagger P<.01$.

$\ddagger P<.001$ (postoperative versus preoperative values).

a weak relationship between prosthetic valve size and regression of LV mass index. Limitations in the Doppler echocardiographic method could cause some underestimation of the effective orifice area. However, this finding might also illustrate a limitation in the effective orifice area index as a measure of prosthetic function. There is a pronounced normal variation in cardiac index, and individuals with an identical effective orifice area index may have quite different transprosthetic flow and pressure gradients. Most patients receiving small prosthetic valves are elderly women, and it is therefore possible that a low physical activity level in these patients further helps to reduce the pressure burden.

Our findings of a reduction in LV mass index in patients with small aortic valve sizes should not be interpreted as an argument that prosthesis-patient mismatch is not a problem. The possibility of obstruction after valve replacement should always be kept in mind when there is a discrepancy between aortic root diameter and body surface area or if the patient is physically active. We have previously shown that it is possible to use a preoperative echocardiographic measurement of the LV outflow tract to identify most of the patients who will receive a small prosthesis. ${ }^{23}$ It is an obvious advantage to know in advance that a patient is likely to receive a small prosthesis, because this will facilitate alternatives such as homograft insertion, enlargement of the aortic root, or supra-annular implantation.

Study limitations. In the present study we investigated patients approximately 2 years after aortic valve replacement. The patients who did not want to participate $(\mathrm{n}=16)$ in the late follow-up and those who died of cardiac related causes $(n=13)$ were preoperatively
Table IV. Factors important for $L V$ mass index regression $(n=80)$ and mean prosthetic Doppler gradient $(n=132)$ analyzed by multiple regression

\begin{tabular}{lrcc}
\hline Variables & $b$ & $95 \%$ CI & P value \\
\hline $\begin{array}{l}\text { LVMI regression } \\
\quad \text { Aortic valve mean pressure }\end{array}$ & 0.76 & 0.42 to 1.11 & .001 \\
$\quad$ gradient & & & \\
$\quad \begin{array}{l}\text { Prosthesis type } \\
\quad \text { Biologic = }\end{array}$ & -21.7 & -37.1 to -6.2 & .007 \\
$\quad$ Mechanical = & & & \\
$\quad$ Prosthesis size & 3.7 & 0.26 to 7.1 & .04 \\
Mean prosthetic Doppler & & & \\
$\quad$ gradient & & & \\
$\quad$ Prosthesis size & -2.1 & -2.7 to -1.5 & .001 \\
$\quad$ Cardiac index & 2.4 & 1.4 to 3.4 & .001 \\
$\quad$ BSA & 11.8 & 6.2 to 17.4 & .001 \\
Prosthesis type & 4.0 & 2.0 to 6.1 & .001 \\
$\quad$ Biologic $=1$ & & & \\
$\quad$ Mechanical =0 & & & \\
\end{tabular}

$\overline{L V M I}$, LV mass index $\left(\mathrm{gm} / \mathrm{m}^{2}\right) ; b$, slope of regression line; $B S A$, body surface area $\left(\mathrm{m}^{2}\right)$.

similar to the study subjects in terms of severity of aortic stenosis, LV mass, and systolic and diastolic function parameters. Therefore it is not likely that our results are importantly biased by this loss of patients.

Another possible cause of bias in the present study is the fact that we do not at our institution use small stented biologic valves (size 19 or $21 \mathrm{~mm}$ ) to avoid prosthesispatient mismatch. It is conceivable that including these valves would have made the overall differences between mechanical and biologic valves more pronounced in terms of prosthesis gradients and LV mass regression.

In this study, we compared pressure gradients and 
effective orifice areas in biologic and mechanical prosthetic heart valves. However, several in vitro studies reveal that valve design influences the flow velocity profile, pressure decrease profile, and calculated orifice area. $^{24,25}$ Localized increased flow velocity and pressure recovery have been shown to cause an overestimation of pressure decrease and underestimation of effective orifice area. This phenomenon is probably most pronounced in bileaflet mechanical valves, ${ }^{25}$ but it has also been claimed to introduce errors in estimations of pressure gradients in biologic valves. ${ }^{26}$ The pressure decreases and calculated effective orifice area in one prosthetic valve type are therefore not necessarily comparable with those found with another valve design. The group of patients with mechanical valves consists of two different valve types, a bileaflet valve (St Jude Medical) and a monoleaflet valve (Omnicarbon). However, the two valve designs do not differ in terms of Doppler echocardiographic findings (peak velocity, gradients, or effective orifice area). ${ }^{9}$ These limitations in the Doppler echocardiographic assessment of prosthesis hemodynamics might explain some of the lack of relation between prosthesis gradients, effective orifice area, and LV mass regression.

Clinical implication. We found more extensive (approximately double) reduction in LV mass index with mechanical prostheses than with bioprostheses of the same size, a finding that might need consideration in the individual choice of prosthetic valve. However, we do not yet know whether a concomitantly possible lower-risk reduction with a bioprosthesis is overbalanced by fewer vascular events.

Small biologic valves (19 and $21 \mathrm{~mm}$ ) often result in obstruction and are usually avoided. This implies that many elderly female patients with narrow aortic roots and a life expectancy that does not exceed that of a biologic prosthesis receive a mechanical valve for hemodynamic reasons. An alternative approach in these elderly patients might be to insert a $23-\mathrm{mm}$ biologic valve after performing an aortic root enlargement or to insert the prosthesis in a supra-annular position. We found no statistically significant differences in hemodynamics or LV mass index regression between 21-mm mechanical valves and 23-mm biologic valves, and the use of biologic valves might beneficially influence the outcome, because it would reduce the complications associated with anticoagulant therapy. However, this would prolong the aortic crossclamp time in a prognostically unfavorable way. ${ }^{27}$

Kjell Pennert, Head of Biometrics, Clinical Data Care AB, Lund, Sweden, gave statistical advice. We thank our col- league Marie Beckman Suurküla for her technical expertise in performing some of the echocardiograms, technicians Annika Karlsson and Magnus Andersson for participating in the interobserver study, and technician Anita Samuelsson for her skilled assistance with the investigations and help with organization. We are also grateful to all the technicians at our echocardiography laboratory for their skilled assistance with the investigation. The collaboration with the hospitals in Western Sweden, making this study possible, is highly appreciated.

\section{REFERENCES}

1. Levy D, Garrison RJ, Savage DD, Kannel WB, Castelli WP. Prognostic implications of echocardiographically determined left ventricular mass in the Framingham heart study. N Engl J Med 1990;322:1561-6.

2. Bech-Hanssen O, Wallentin I, Houltz E, Beckman Suurküla M, Larsson S, Caidahl C. Gender differences in patients with severe aortic stenosis: impact on preoperative left ventricular geometry and function, as well as early postoperative morbidity and mortality. Eur J Cardiothorac Surg 1999;15:24-30.

3. Abdelnoor M, Nitter-Hauge S, Trettli S. Relative survival of patients after heart valve replacement. Eur Heart J 1990;11:23-8.

4. Morris JJ, Schaff HV, Mullany CJ, Rastogi A, McGregor CGA, Daly RC, et al. Determinants of survival and recovery of left ventricular function after aortic valve replacement. Ann Thorac Surg 1993;56:22-30.

5. González-Juanatey JR, García-Acuña JM, Fernandez MV, Cendón AA, Fuentes VC, García-Bengoechea JB, et al. Influence of the size of aortic valve prostheses on hemodynamics and change in left ventricular mass: implication for surgical management of aortic stenosis. J Thorac Cardiovasc Surg 1996;112:27380.

6. Sim EK, Orszulak TA, Schaff HV, Shub C. Influence of prosthesis size on change in left ventricular mass following aortic valve replacement. Eur J Cardiothorac Surg 1994;8:293-7.

7. Monrad ES, Hess OM, Murakami T, Nonogi H, Corin WJ, Krayenbuehl HP. Time course of regression of left ventricular hypertrophy after aortic valve replacement. Circulation 1988;77: 1345-55.

8. De Paulis R, Sommariva L, Colagrande L, De Matteis GM, Fratini S, Tomai F, et al. Regression of left ventricular hypertrophy after aortic valve replacement for aortic stenosis with different valve substitutes. J Thorac Cardiovasc Surg 1998;116:590-8.

9. Bech-Hanssen O, Wallentin I, Larsson S, Caidahl K. Reference Doppler echocardiographic values for St. Jude Medical, Omnicarbon and Biocor prosthetic valves in the aortic position. J Am Soc Echocardiogr 1998;11:466-77.

10. Sahn DJ, DeMaria A, Kisslo J, Weyman A. Recommendations regarding quantification in M-mode echocardiography: results of a survey of echocardiographic measurements. Circulation 1978; 58:1072-83.

11. Teichholz LE, Kreulen T, Herman MV, Gorlin R. Problems in echocardiographic volume determinations: echocardiographicangiographic correlations in the presence or absence of asynergy. Am J Cardiol 1976;37:7-11.

12. Devereux RB, Alonso DR, Lutas EM, Gottlieb GJ, Campo E, Sachs I, et al. Echocardiographic assessment of left ventricular hypertrophy: comparison to necropsy findings. Am J Cardiol 1986;5 7:450-8. 
13. Skjaerpe T, Hegranaes L, Hatle L. Noninvasive estimation of valve area in patients with aortic stenosis by Doppler ultrasound and twodimensional echocardiography. Circulation 1985;72: 810-8.

14. Arakawa M, Akamatsu S, Terazawa E, Dohi S, Miwa H, Kagawa $\mathrm{K}$, et al. Age-related increase in systolic fraction of pulmonary vein flow velocity-time integral from transesophageal Doppler echocardiography in subjects without cardiac disease. Am J Cardiol 1992;70:1190-4.

15. Ota T, Iwahashi K, Matsuda H, Tsukube T, Ataka K, Okada M. Reduction of left ventricular hypertrophy with St Jude Medical $19 \mathrm{~mm}$ valve prosthesis. Angiology 1995;46:981-7.

16. Krayenbuehl HP, Hess OM, Monrad ES, Schneider J, Mall G, Turina M. Left ventricular myocardial structure in aortic valve disease before, intermediate, and late after aortic valve replacement. Circulation 1989;79:744-55.

17. Hess OM, Ritter M, Schneider J, Grimm J, Turina M, Krayenbuehl HP. Diastolic stiffness and myocardial structure in aortic valve disease before and after valve replacement. Circulation 1984;69:855-65.

18. Villari B, Vassalli G, Betocchi S, Briguori C, Chiariello M, Hess OM. Normalization of left ventricular nonuniformity late after valve replacement for aortic stenosis. Am J Cardiol 1996;78:66-71.

19. St. John Sutton M, Plappert T, Spiegel A, Raichlen J, Douglas P, Reichek N, et al. Early postoperative change in left ventricular chamber size, architecture, and function in aortic stenosis and aortic regurgitation and their relation to intraoperative change in afterload: a prospective two-dimensional echocardiographic study. Circulation 1987;76:77-89.

20. Teoh KH, Fulop JC, Weisel RD, Ivanov J, Tong CP, Slattery SA, et al. Aortic valve replacement with a small prosthesis. Circulation 1987;76(Suppl):III123.

21. Rahimtoola S. The problem of valve prosthesis-patient mismatch. Circulation 1978;58:20-4.

22. Dumesnil JG, Honos GN, Lemieux M, Beauchemin J. Validation and applications of indexed aortic prosthetic valve areas calculated by Doppler echocardiography. J Am Coll Cardiol 1990;16: 637-43.

23. Bech-Hanssen O, Caidahl K, Mykén PUS, Kjellman U, Larsson S, Wallentin I. Preoperative echocardiographic prediction of small prostheses at aortic valve replacement. J Heart Valve Dis 1996;5:128-35.

24. Baumgartner H, Khan S, DeRobertis M, Czer L, Maurer G. Discrepancies between Doppler and catheter gradients in aortic prosthetic valves in vitro: a manifestation of localized gradients and pressure recovery. Circulation 1990;82:1467-75.

25. Baumgartner H, Khan S, DeRobertis M, Czer L, Maurer G. Effect of prosthetic aortic valve design on the Doppler-catheter gradient correlation: an in vitro study of normal St. Jude, Medtronic-Hall, Starr-Edwards and Hancock valves. J Am Coll Cardiol 1992;19:324-32.

26. Stewart SFC, Nast EP, Arabia FA, Talbot TL, Proschan M, Clark RE. Errors in pressure gradient measurement by continuous wave Doppler ultrasound: type, size and age affects bioprosthetic valves. J Am Coll Cardiol 1991;18:769-79.

27. Abdelnoor M, Hall KV, Nitter-Hauge S, Lindberg H, Øvrum E. Prognostic factors in aortic valve replacement associated with narrow aortic roots. Scand J Thorac Cardiovasc Surg 1986;20: 227-32. 